\title{
Status Karbon Organik dan Nitrogen Total Tanah serta Pertumbuhan Jagung (Zea mays 1.) Akibat Aplikasi Fungi Selulolitik Indigenous dan Jerami Padi pada Inceptisol Aceh
}

\author{
(The Statuses Soil Organic Carbon and Total Nitrogen Due to Application of \\ Indigenous Cellulolytic Fungi and Rice Straw on Inceptisol's Aceh) \\ Eva Disniwati ${ }^{1}$, Munawar Khalil ${ }^{1}$, Fikrinda Fikrinda ${ }^{1 *}$ \\ ${ }^{1}$ Program Studi Ilmu Tanah, Fakultas Pertanian, Universitas Syiah Kuala \\ *Corresponding author: fikrinda@unsyiah.ac.id
}

\begin{abstract}
Abstrak. Produktivitas Inceptisol sebagai lahan budidaya dibatasi oleh rendahnya kadar bahan organik dan ketersediaan beberapa unsur hara makro. Penelitian ini menggunakan rancangan acak kelompok dengan tiga ulangan untuk menguji pengaruh aplikasi fungi selulolitik indigenous yang berasal dari Inceptisol Aceh (tanpa fungi selulolitik, Talaromyces pinophilus strain MR107 dan Purpureocillium lilacinum isolate PIGD23i) dan jerami padi (tanpa jerami padi, $10 \mathrm{t} \mathrm{ha}^{-1}$ dan $20 \mathrm{t} \mathrm{ha}^{-1}$ ) terhadap karbon (C-organik) dan nitrogen (N-total) tanah serta berat basah dan berat kering berangkasan atas tanaman pada Inceptisol. Hasil penelitian menunjukkan bahwa inokulasi kedua inokulan fungi selulolitik indigenous dan jerami padi pada berbagai dosis aplikasi memberikan pengaruh yang sama terhadap status $\mathrm{C}$-organik dan $\mathrm{N}$-total tanah serta pertumbuhan jagung pada Inceptisol Aceh.
\end{abstract}

Kata kunci: Talaromyces, Purpureocillium, Bahan Organik, Inceptisol.

\begin{abstract}
The productivity of Inceptisols as cultivated land has problems in low organic matter and macronutrients. This study arranged in a randomized block design and three replications to examine the effect of indigenous cellulolytic fungi from Inceptisol Aceh and rice straw on soil organic carbon (SOC) and total nitrogen (total-N) and the weight of the upper part of the plant on Inceptisol. The cellulolytic fungi treatments were no cellulolytic fungi, Talaromyces pinophilus strain MR107 and Purpureocillium lilacinum isolate PIGD23i. The rice straw application consisted of without rice straw, $10 \mathrm{t} \mathrm{ha}^{-1}$, and $20 \mathrm{t} \mathrm{ha}^{-1}$. The results showed that both indigenous cellulolytic fungi and rice straw at various dose applications gave the same effect on the soil $\mathrm{C}$-organic and N-total status and the maize growth on Inceptisols Aceh.
\end{abstract}

Keywords: Talaromyces, Purpureocillium, Organic Matter, Inceptisol.

\section{PENDAHULUAN}

Inceptisol merupakan tanah yang tersebar luas di Indonesia dengan luas kurang lebih 70,52 juta hektar atau 40\% dari total luas daratan di Indonesia (Tarigan, 2018). Tanah ini memiliki luas sekitar 32,084 ha dari 290.350 atau sekitar 11,05\% dari luas Kabupaten Aceh Besar (BPS, 2016). Di Aceh tanah ini umumnya ditemukan sebagai lahan kering yang belum banyak dimanfaatkan secara maksimal karena rendahnya rata-rata curah hujan tahunan yang mengakibatkan keterbatasan ketersediaan air pada musim kemarau disamping rendahnya status kesuburan tanah (Muyassir et al., 2012).

Penggunaan Inceptisol sebagai lahan budidaya tanaman memiliki masalah dengan $\mathrm{pH}$ tanah masam, kandungan bahan organik yang rendah, dan unsur hara $\mathrm{N}, \mathrm{P}$, dan $\mathrm{K}$ yang rendah (Arviandi et al., 2015). Karena itu diperlukan upaya-upaya meningkatkan produktivitas tanah tersebut sebagai lahan budidaya tanaman.

Penggunaan bahan organik merupakan praktek yang sering dilakukan untuk meningkat kesuburan tanah (Habi, 2012). Praktek pengelolaan tanah ini berperan dalam meningkatkan unsur hara (Sentana, 2010) kapasitas tukar kation (KTK), aktivitas mikrooganisme tanah, memperbaiki struktur tanah, drainase, tata udara dan daya serap tanah terhadap air (Lestari, 2015). 
Jerami padi merupakan limbah pertanian yang potensial sebagai sumber bahan organik. Namun, pengunaannya dihadapkan pada kendala lambatnya proses dekomposisi karena tingginya rasio $\mathrm{C} / \mathrm{N}$ pada limbah tersebut. Untuk mempercepat proses tersebut diperlukan bantuan dekomposer, salah satunya adalah fungi selulolitik (Irawan, 2008).

Fungi selulolitik berperan penting dalam mendegradasi senyawa organik menjadi mineral yang dibutuhkan tanaman (Modes, 2019). Aktivitas selulase yang dimilikinya mempengaruhi kemampuan mikroorganisme ini dalam mendegradasi selulosa yang terkandung pada limbah organik seperti jerami padi. Beberapa penelitian menunjukkan bervariasinya aktvitas selulase dari mikroorganisme ini. Hasil penelitian Tridasma (2009) menunjukkan bahwa fungi selulolitik Trichoderma viride dan Gliocladium sp. mampu mempercepat proses degradasi pada beberapa jenis limbah pertanian.

Inokulasi fungi selulolitik juga dilaporkan dapat meningkatkan kesuburan dan kesehatan media tanam (Pramanik et al., 2017; Fikrinda et al., 2020) sehingga mempengaruhi pertumbuhan tanaman (Fikrinda et al., 2019; Nasrullah et al., 2019) Berdasarkan pemikiran tersebut penelitian ini ingin mengetahui pengaruh fungi selulolitik dan jerami padi terhadap C-organik dan N-total tanah serta pertumbuhan jagung pada Inceptisol.

\section{METODE PENELITIAN}

\section{Tempat dan Waktu Penelitian}

Penelitian ini dilaksanakan di Laboratorium Biologi Tanah Fakultas Pertanian Universitas Syiah Kuala, Rumah Kasa Fakultas Pertanian Universitas Syiah Kuala dan Laboratorium Penelitian Tanah dan Tanaman Fakultas Pertanian Universitas Syiah Kuala. Penelitian ini berlangsung sejak Desember 2019 sampai dengan Juni 2020.

\section{Rancangan Percobaan}

Rancangan percobaan yang digunakan dalam penelitian ini menggunakan Rancangan Acak Kelompok (RAK) faktorial 3 x 3 dan 3 (tiga) kelompok. Dua faktor yang diuji yaitu jenis fungi selulolitik (tanpa fungi selulolitik, Talaromyces pinophilus strain MR107 dan Purpureocillium lilacinum isolate PIGD23i) dan dosis jerami (tanpa jerami padi, $10 \mathrm{t} \mathrm{ha}^{-1}$ dan $20 \mathrm{tha}^{-1}$ ).

\section{Pelaksanaan Penelitian}

\section{Penyiapan Media Tanam}

Bahan tanah Inceptisol yang digunakan berasal dari kawasan University Farm Universitas Syiah Kuala, Gampong Ie Seuum Kecamatan Mesjid Raya Kabupaten Aceh Besar dengan titik koordinat $05^{\circ} 34^{\prime} 25^{\prime \prime}$ LU dan $095^{\circ} 32^{\prime} 12^{\prime \prime}$ BT. Hasil analisis awal sifat kimia tanah sebelum perlakuan dapat dilihat pada Tabel 1.

Tabel 1. Hasil analisis awal sifat kimia tanah

\begin{tabular}{llcl}
\hline No & Parameter & Nilai & Kriteria \\
\hline 1 & $\mathrm{pH}\left(\mathrm{H}_{2} \mathrm{O}\right)$ & 6,70 & Netral \\
2 & C-organik $(\%)$ & 0,76 & Sangat Rendah \\
3 & Bahan Organik & 1,31 & Sangat Rendah \\
4 & N-total $(\%)$ & 0,11 & Rendah \\
5 & $\mathrm{C} / \mathrm{N}$ & 6,90 & Rendah \\
6 & P-tersedia $\left(\mathrm{mg} \mathrm{kg}^{-1}\right)$ & 5,85 & Sangat Rendah \\
7 & K-dd $\left(\mathrm{cmol}_{(+)} \mathrm{kg}^{-1}\right)$ & 0,67 & Tinggi \\
\hline
\end{tabular}


Bahan tanah sebagai media tanam diambil pada kedalaman $0-20 \mathrm{~cm}$. Selanjutnya bahan tanah tersebut dibersihkan dari ranting serta perakaran dan dikering-anginkan, ditumbuk serta diayak dengan ayakan berdiameter lubang $5 \mathrm{~mm}$ sebelum dimasukkan ke dalam pot-pot percobaaan. Setiap pot diisi tanah sebanyak $10 \mathrm{~kg}$.

\section{Penyiapan dan Aplikasi Jerami Padi sebagai Sumber Bahan Organik}

Jerami padi berukuran $2 \mathrm{~cm}$ yang digunakan terlebih dahulu dicuci bersih, dikering anginkan selama dua hari dan disterilkan dengan autoklaf pada suhu $121^{\circ} \mathrm{C}$ selama 30 menit. Bahan jerami padi yang digunakan memiliki $\mathrm{pH} 8,28$, C-organik 22,99\%, N-total $0,16 \%, \mathrm{P}_{2} \mathrm{O}_{5}$ $0,1 \%$ dan $\mathrm{K}_{2} \mathrm{O}$ 0,04\% dan $\mathrm{C} / \mathrm{N}$ 143,68. Aplikasi jerami padi sesuai perlakuan dilakukan dengan mencampurkannya secara merata pada media tanam. Selanjutnya media tanam tersebut disiram hingga kapasitas lapang dan diinkubasi selama 30 hari sebelum dilakukan penanaman benih jagung.

\section{Penyiapan dan Aplikasi Inokulan Fungi Selulolitik}

Isolat fungi selulolitik Talaromyces pinophilus strain MR107 dan Purpureocillium lilacinum isolat PIGD23i) yang digunakan sebagai inokulan terlebih dahulu dibiakkan dalam medium Mandel cair steril dengan penambahan 0,5\% (b/v) glukosa dan 2\% (v/v) Tween 80 selama tiga hari sebelum diinokulasikan dalam jerami padi sebagai media pembawa. Inokulan digunakan setelah diinkunbasi selama dua bulan dan memiliki kepadatan spora $352 \times 10^{6}$ spora $\mathrm{ml}^{-1}$. Aplikasi inokulan fungi selulolitik sebanyak $20 \mathrm{~g} \mathrm{pot}^{-1}$ dilakukan bersamaan dengan pengaplikasian jerami padi sebagai bahan organik.

\section{Pengamatan}

\subsection{C-organik dan N-total tanah}

Sampel tanah yang digunakan untuk pengamatan C-organik dan N-total tanah berasal dari rizosfer jagung berumur 45 hari setelah tanam (HST). Metode analisis yang digunakan adalah Walkey and Black untuk C-organik dan Kjeldahl untuk N-total.

\subsection{Berat Basah dan Berat Kering Berangkasan Atas Tanaman}

Berat berangkasan basah tanaman diambil setelah tanaman berumur 45 hari setelah tanam (HST) dengan cara pangkal batang dipotong $10 \mathrm{~cm}$ dari permukaan pot. Kemudian berangkasan tanaman tersebut ditimbang dengan menggunakan neraca analitik.

Berat berangkasan kering tanaman yang dipisahkan dari akarnya kemudian dimasukkan dalam kantong kertas berlubang dan dikeringkan dalam oven. Penimbangan berat berangkasan kering tanaman dilakukan setelah tanaman diovenkan pada suhu $60{ }^{\circ} \mathrm{C}$ selama 48 jam.

\section{Analisis Data}

Uji normalitas dilakukan terhadap data yang diperoleh, kemudian dianalisis dengan analisis ragam statistik atau analysis of variance (ANOVA) menggunakan Microsoft Office Excel.

\section{HASIL DAN PEMBAHASAN}

\section{C-organik Tanah}

Hasil penelitian (Gambar 1) memperlihatkan bahwa fungi selulolitik dan jerami padi tidak nyata mempengaruhi $\mathrm{C}$-organik tanah. Kadar C-organik yang sangat rendah (Tabel 1) 
menghambat aktivitas dekomposisi inokulan fungi selulolitik maupun mikrorganisme lokal dalam menyumbang unsur hara tersebut ke tanah. Hanafiah et al. (2010) menyatakan bahwa karbon sebagai sumber energi dan nutrisi untuk mikroorganisme tanah.

Status C-organik tanah yang sangat rendah (Tabel 1) dan sangat tingginya $\mathrm{C} / \mathrm{N}$ jerami padi $(143,68)$ yang diaplikasikan juga mempengaruhi sumbangan unsur tersebut ke tanah. Kondisi ini menyebabkan tidak berbedanya status C-organik tanah diantara perlakuan dosis jerami padi yang dicobakan. Menurut Damanik et al. (2011) bahan organik dengan C/N yang sama atau mendekati tanah dapat digunakan secara langsung, tetapi jika $\mathrm{C} / \mathrm{N}$ tinggi harus didekomposisi terlebih dahulu hingga melapuk dengan nilai sebesar 10-12.

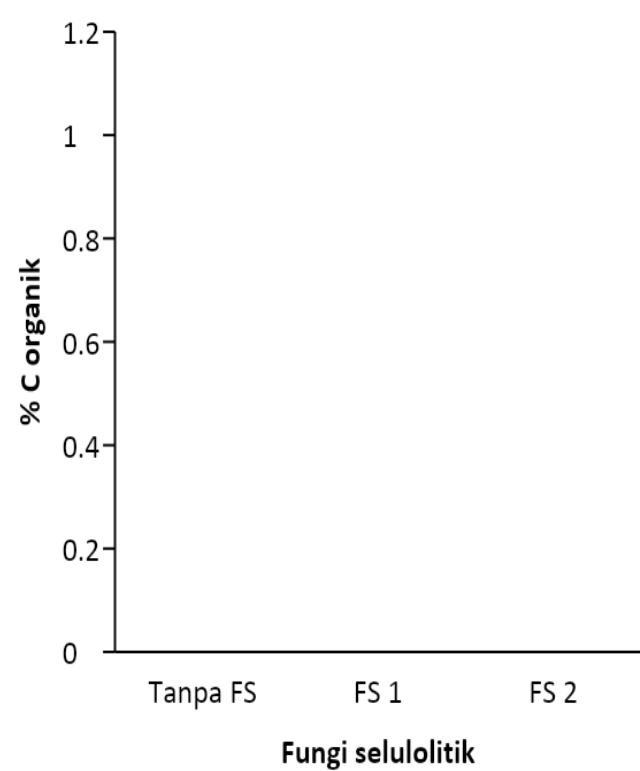

(a)

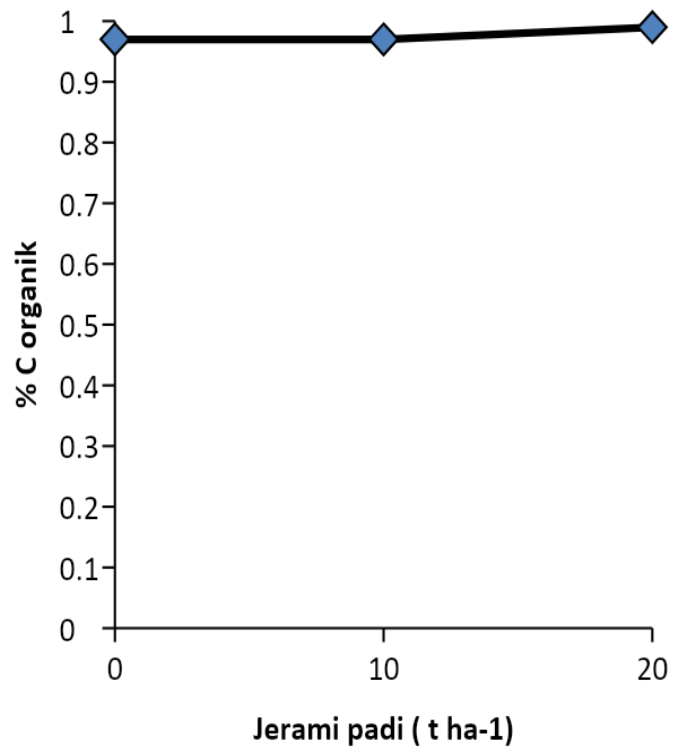

(b)

Gambar 1. Kadar C-organik tanah akibat pengaruh fungi selulolitik (a) dan jerami padi (b) Keterangan: FS = Fungi selulolitik; FS 1= Talaromyces pinophilus strain MR107;

FS 2 = Purpureocillium lilacinum isolate PIGD23i.

\section{N-total Tanah}

Hasil penelitian (Tabel 2) menunjukan bahwa fungi selulolitik dan jerami padi tidak nyata mempengaruhi $\mathrm{N}$-total tanah.

Tabel 2. Rata-rata N-total tanah akibat pengaruh fungi selulolitik dan jerami padi.

\begin{tabular}{ll}
\hline \multicolumn{1}{c}{ Perlakuan } & $\% \mathrm{~N}$ \\
\hline Fungi Selulolitik & 0,10 \\
Tanpa Fungi Selulolitik & 0,10 \\
Talaromyces pinophilus strain MR107 & 0,11 \\
Purpureocillium lilacinum isolate PIGD23i & \\
Jerami Padi & 0,10 \\
Tanpa jerami padi & 0,11 \\
$10 \mathrm{tha}^{-1}$ & 0,11 \\
$20 \mathrm{t} \mathrm{ha}^{-1}$ & \\
\hline
\end{tabular}


Seperti halnya terhadap C-organik tanah, kedua inokulan fungi selulolitik yang diinokulasikan memberikan pengaruh yang sama dengan perlakuan tanpa fungi selulolitik terhadap N-total tanah. Rendah kadar N tanah (Tabel 1) diduga menghambat mikroorganisme tanah, termasuk fungi selulolitik tersebut. Nitrogen merupakan unsur hara makro yang dibutuhkan mikroorganisme untuk tumbuh dan beraktivitas (Laik et al., 2009). Selain itu, kemampuan fungi selulolitik melepaskan $\mathrm{N}$ yang berasosiasi dengan bahan organik tanah terkendala oleh rendahnya bahan organik tanah (Tabel 1) sebagai sumber hara termasuk nitrogen. Menurut Wijanarko et al. (2012) Ketersediaan hara N dalam tanah dipengaruhi oleh laju mineralisasi bahan organik.

Pemberian jerami padi dengan beberapa dosis tidak nyata meningkatkan N-total tanah. Hal ini diduga berhubungan dengan sangat tingginya nilai $\mathrm{C} / \mathrm{N}$ limbah jerami padi yang diaplikasikan sehingga $\mathrm{N}$ diimobilisasikan oleh mikroba tanah. Hal ini menyebabkan aplikasi jerami padi tersebut tidak dapat menyuplai unsur tersebut ke tanah yang memiliki kadar $\mathrm{N}$ total rendah (Tabel 1). Salah satu faktor yang mempengaruhi kadar N-total tanah adalah kualitas bahan organik yang masuk ke dalam tanah. Setiawati et al. (2019) menyatakan bahwa mineralisasi bahan organik dengan rasio $\mathrm{C} / \mathrm{N}$ tinggi akan berjalan lambat dan menyebabkan N-total tanah terimmobilisasi.

\section{Berat Basah dan Berat Kering Atas Tanaman}

Hasil penelitian (Gambar 2) menunjukan bahwa fungi selulolitik dan jerami padi tidak nyata mempengaruhi berat basah dan kering berangkasan atas tanaman.

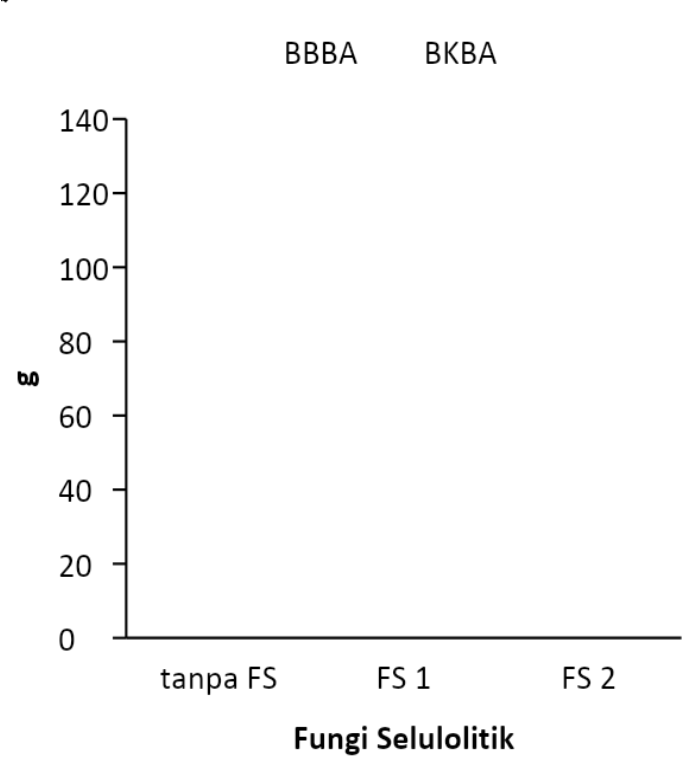

(a)

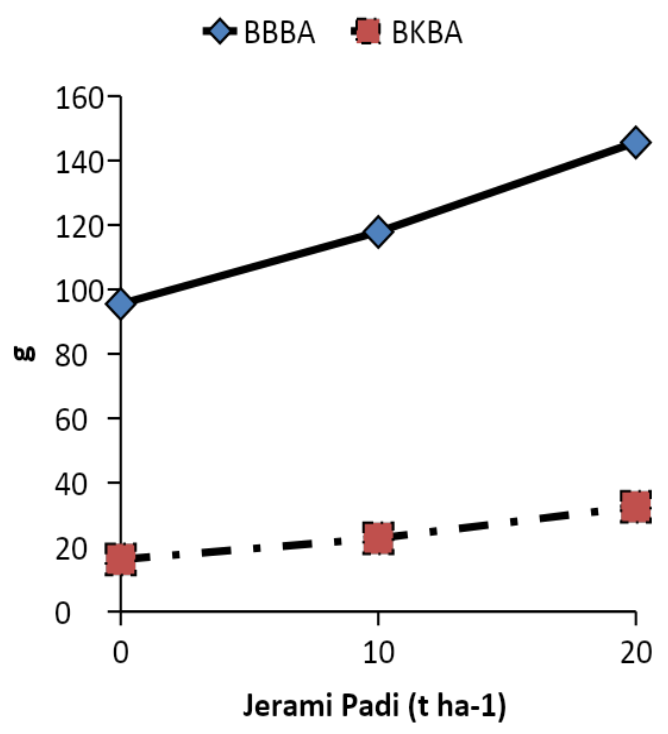

(b)

Gambar 2. Berat basah (BBBA) dan berat kering (BKBA) tanaman akibat pengaruh fungi selulolitik (a) dan jerami padi (b).

Keterangan: $\mathrm{BBBA}=$ berat basah berangkasan atas; $\mathrm{BKBA}=$ berat kering berangkasan atas.

Hasil penelitian menunjukkan bahwa nitrogen merupakan hara yang sangat diperlukan untuk meningkatkan bagian-bagian vegetatif tanaman seperti daun, batang, dan akar Gusniawati et al. (2008). Selain itu, efesiensi penyerapan unsur hara rendah menyebabkan 
kurangnya unsur hara pada tanaman dapat mengganggu proses laju penimbunan fotosintat sehingga biomassa tanaman lebih rendah (Hawalid, 2019; Nurhanafi et al., 2017).

\section{KESIMPULAN}

Inokulan fungi selulolitik indegenos dan jerami padi pada beberapa dosis aplikasi tidak nyata mempengaruhi kadar C-organik dan $\mathrm{N}$-total tanah serta berat basah dan berat kering berangkasan atas tanaman jagung (Zea mays L.) pada Inceptisol Aceh.

\section{DAFTAR PUSTAKA}

Arviandi, R., A. Rauf dan G. Sitanggang. 2015. Evaluasi sifat kimia tanah Inceptisol pada kebun inti tanaman gambir di Kecamatan Salak Kabupaten Pakpak Bharat. Agroteknologi. 3(4): 1329-1334.

Badan Pusat Statistik. 2016. Aceh Besar dalam Angka. Badan Pusat Statistik, Banda Aceh.

Damanik, M.M.B., E.H. Bachtiar Fauzi., Sarifuddin, dan Hamidah. 2011. Kesuburan Tanah dan Pemupukan. Universitas Sumatra Utara Press, Medan.

Fikrinda, F., S. Syafruddin, S. Sufardi dan R. Sriwati. 2019. Combined application of native mycorrhizal and cellulolytic fungi to manage drought effects on maize. IOP Conference Series: Earth and Environmental Science. 334 (1): 012072.

Fikrinda, F., S Syafruddin, S. Sufardi dan R. Sriwati. 2020. Comparative Potential of Different Native Mycorrhizal and Cellulolytic Fungi in Recovering Soil Biological Quality under Water Deficit. Sys Rev Pharm 2020. 11(2): 193 - 200.

Habi, M.L. 2012. Ketersediaan fosfat, serapan fosfat dan hasil tanaman jagung akibat pemberian bokashi ela sagu dengan pupuk fosfat pada Inceptisol. Buana Sains. 12(1): 63-70.

Hanafiah, A.S., T. Sabrina dan H. Guchi. 2010. Biologi dan ekologi tanah. Fakultas Pertanian, Universitas Sumatra Utara, Medan.

Hawalid, H. 2019. Respon pertumbuhan dan produksi jagung manis (Zea mays L. saccharata Sturt) dengan pemberian pupuk organik dan anorganik di lahan lebak. Klorofil. 14(1): 35-40.

Irawan, B. 2008. Uji aktivitas enzim selulase dan lipase pada mikrofungi selama proses dekomposisi limbah cair kelapa sawit dengan pengujian kultur murni. Skripsi. Jurusan Biologi, Fakultas Matematika dan Ilmu Pengetahuan Alam, Universitas Lampung.

Gusniawati., N. Fatia dan R. Arif. 2008. Pertumbuhan dan hasil tanaman jagung dengan pemberian kompos alang-alang. Agronomi. 12( 2): 37-52.

Laik, R, K., Kumar., D.K. Das dan O.P. Chaturvedi. 2009. Labile soil organic matter pools in a Calciorthent after 18 years of afforestation by different plantations. Applied Soil Ecology. 42(2) : 71-78.

Lestari, E. P. 2015. Respons pemberian pupuk hayati pada beberapa jarak tanam pertumbuhan dan produksi kailan (Brassica oleraceae var. acephala). Skripsi. Universitas Sananta Darma, Yogyakarta.

Muyassir, Sufardi, dan Saputra. 2012. Perubahan sifat kimia entisol Krueng Raya akibat komposisi jenis dan takaran kompos organik. Lentera. 12(3): 37-47.

Meryandini A., W. Widosari., B. Maranatha., T.C. Sunarti., N. Rachmania., H. Satria. 2009. Isolasi bakteri selulotik dan karakterisasi enzimnya. Makara Sains. 13(1): 33-38. 
Modes, C. 2019. Eksplorasi fungi selulolitik dari tanah di bawah tumbuhan raru (Cotylelobium sp.) di Desa Bonalumban, Kecamatan Tukka, Kabupaten Tapanuli Tengah. Skripsi. Departemen Budidaya Hutan, Fakultas Kehutanan, Universitas Sumatera Utara, Medan.

Nasrullah, Sufardi, Ashabul Anhar dan Fikrinda. 2018. The effect of indigenous arbuscular mycorrhizal fungi and production of maize (Zea mays L.) under drought stress in Inceptisol of Aceh. Int. J. Adv. Res. 6(12): 1047-1055.

Nurhanafi, A.W., D. Indradewa dan R. Rogomulyo. 2017. Pertumbuhan dan hasil jagung (Zea mays L.) pada pola tanam satu lubang dengan kedelai (Glycine max L. Merrill). Vegetalika. 6(4): 1-13.

Pramanik, P., S. Safique., A. Zahan., M. Phukan dan S. Ghosh. 2017. Cellulolytic microorganisms control the availability of nitrogen in microcosm of shredded pruning litter treated highly acidic teagrowing soils of Assam in Northeast India. Applied Soil Ecology. 120: 30-34.

Sentana, S. 2010. Pupuk organik, peluang dan kendalanya. Pengembangan Teknologi Kimia untuk Pengolahan Sumber Daya Alam Indonesia. ISSN 1693-4392.

Setiawati, M.R., N. Ufah., R. Hindersah dan P. Suryatmana. 2019. Peran mikroba dekomposer selulolitik dari sarang rayap dalam menurunkan kandungan selulosa limbah pertanian berselulosa tinggi. Tesis. Program Pascasarjana Universitas Padjadjaran, Bandung.

Sudirja, R. 2007. Respon beberapa sifat Kimia Inceptisol asal Rajamandala dan hasil bibit Kakao melalui pemberian pupuk organik dan pupuk hayati. Laporan Hasil Penelitian Dosen Muda. Fakultas Pertanian, Universitas Padjadjaran, Bandung.

Tarigan, A.P. 2018. Perubahan beberapa sifat kimia tanah Inceptisol dan pertumbuhan tanaman jagung (Zea mays L.) akibat pemberian kompos kulit durian dan pupuk sp3. Skripsi. Program studi Agroteknologi, Fakultas Pertanian, Universitas Sumatera Utara, Medan. 